\title{
PERANCANGAN PERTUNJUKAN TEATER RAMBUN PAMENAN DALAM POLA TEATER TRADISIONAL RANDAI DENGAN PENDEKATAN TEATER MODERN (WELL MADE PLAY)
}

\author{
Ikhsan Haryanto ${ }^{1}$, Yusril ${ }^{2}$, Martarosa ${ }^{3}$ \\ Minat Studi Penciptaan Seni Teater Program Pascasarjana \\ Institut Seni Indonesia Padangpanjang \\ Jl. Bahdr Johan, Guguak Malintang, Padangpanjang, Kota Padangpanjang, 27126 \\ Sumatera Barat. Indonesia \\ Email:mhachan1991@gmail.com,yusril@isipp.ac.id,martarosa@isipp.ac.id.
}

\begin{abstract}
Abstrak
Perancangan pertunjukan teater Rambun Pamenan ini bertujuan untuk menggarap randai dengan mengadaptasi konsep teater modern. Pola yang digunakan dalam garapan ini adalah pola randai, tetapi untuk aktingnya menggunakan pemeranan presentatif (realis tik). Metode penciptaan yang digunakan pada perancangan ini adalah metode pelatihan aktor oleh Rich ard Boleslavsky. Karya yang dihasilkan dari proses kreatif ini adalah sebuah pertunjukan teater modern dengan pola randai. Perancangan pertunjukan teater modern berbasis tradisi ini merupakan penciptaan formula baru dari berbagai idiom idiom tradisi yang dipergunakan sebagai titik tolak dalam berkarya.
\end{abstract}

Kata Kunci: rambun pamenan, randai, teater modern.

\begin{abstract}
Theater Design Rambun Pamenan is designed to work on randai by adapting the concept of modern theater. The pattern used in this claim is the randai pattern, but for acting it uses a presentative (realistic) cast. The Selection Method used in this design is the actor training method by Richard Boleslavsky. The work produced from this creative process is a modern theater work with randai patterns. The design of traditional theater shows based on tradition is a new formula from traditional idioms which are used as a starting point in the making.
\end{abstract}

Keywords: rambun, pamenan, randai, modern theater.

\section{PENDAHULUAN}

Teater merupakan seni kolektif bahkan ditinjau dari proses perwujudanya merupakan seni luluhan atau sintetic art. Teater merupakan seni yang luas sekali, lebih luas dari semua seni yang kita kenal dalamhidup ini. Dalam teater hampir semuacabang seni kita jumpai sebagai faktor pendukung, misalnya: seni sastra, seni rupa, seni tari, seni musik dan masih banyak lagi. Semua itu dirangkai menjadi satu kesatuan yang bulat dan utuh. Rangkaian semacam itu salah satunya bias kita temukan dalam teater tradisional randai di Minangkabau.

Randai yang berkembang di Minangkabau, hidupnya bertolak dari khasanah tradisi masyarakat Minangkabau. Teater tradisional ini telah menjadi milik seluruh masyarakat Minangkabau dan dinikmati hampir di semua kalangan masyarakat setempat. Pertunjukan randai ini dilakukan dalam bentuk arena, disamping penonton dalam formasi melingkar. Permainan gelombang (gerak dari dalam pola pencak silat tradisional Minangkabau) ditampilkan dalam arena lingkaran. Adegan-adegan, acting, dan dialogdialog pelaku dimainkan dalam lingkaran tersebut.

Secara historis, ketika mementaskan Randai tradis ional Minangkabau ceritany adimainkan tanpa menggunakan naskah. Hal terpenting adalah bagaimana pemain mengenal jalan ceritanya serta watak tokoh yng akan diperankan. Halsemacamini tentunya akan membawa kelemahan-kelemahan, antara lain, ketidaktepatan dan kurang lancarnya dialog para pemeran dan urutan kontinuitas adegan. Sedangkan lakon randai yang akan menjadi bahan acuan dalam penciptaan ini adalah Randai "Rambun Pamenan" yang sudah berbentuk sebagainaskah.

Naskah Randai"Rambun Pamenan" ini adalah menjadi pangkal tolak sebuah pementasan, karena dengan pertimbangan, naskah itu tidak dapat dihayati secara utuh hanya sebagai karya sastrabelaka. Pada akhimya, kemampuan potensial sebuah naskah Randaibaru akan nyata dilihat pada sebuah pementasan yang 


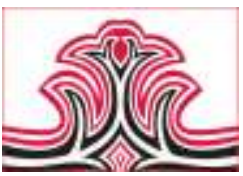

keberhasilan pementasannya sangat tergantung oleh seorang pemain randai.

Pemeran atau pemain randai merupakan potensi ( kekuatan ) kreatif yang cukup penting dalam teater. Dia yang menentukan berhasil atau tidaknya suatu pertunjukan disamping faktor pendukung lainnya. Pekerjaan menjadi seorang aktor atau pemeran sangatlah berat, apalagi ketika berperan sebagai pemeran dalam Randai. Alas an yang cukup penting: aktor didalam permainan Randai tidak hanya menjadi tokoh akantetapi juga memerankan peran yang lain. Diantaranya, pemain gelombang dan pendendang.

Tuntutan yang cukup berat atas pemain Randai akan terlihat karena ia tidak hanya mempertunjukan emosi yang menyatakan pernyataan simbolis secara umum. Juga tidak hanya menyesuaikan diri dengan struktur watak yang ditentukan pengarang akan tetapi ia harus pula mewujudkan emosi-emosi tentang cirri-ciri pribadinya yang karekteristik. Hal inilah yang kemudian mendorong diperlukannya seorang sutradara yang menjadi pengarah dan pemimpin proses kreatif randai secara keseluruhan.

Seorang sutradara akan meninjau lakon dari sudut kemungkinan-kemungkinan penggarapan, penyajian, dan pementasan. Berangkat dari pertimbangan di atas pencipta (yang sekaligus seorang Sutradara) memilih lakon ”Rambun Pamenan.

Naskah "Rambun Pamenan" inimengandung pelajaran pentinga bahwa Raja alim Raja disambah dan Raja zalim Raja dis anggah. Artinya, ketika siapapun mampu untuk menempatkan kekuasaan dengan baik, maka siapapun akan mendapat pujian dan penghargaan dari orang lain. Tapi kalau kita salah mempergunakan kekeuasaan itu(sewenang-wenang) maka kita mendapat cacian, makian dan malapetaka dari pihak luar.

Naskah ini juga memiliki kemungkinan untuk digarap kedalam sebuah pertunjukan teater tradisional (Randai ) dengan mengadaftasinya dalam konsep Well Made Play sebagaimana dalamteater moderen. Konsep yang dimaksud adalah mewuju dkan pementasan randai yang menempatkan suspen, alur cerita dan penyelasaian secara jelas dan logis. Selain itu, pertimbangan lain adalah ketepatan muatan yang terkandung dalam naskah ini yang sarat dengan pembelajaran adat dan agama dan permasalahan yang masih terasa pantas dikomunikasikan kepada penonton pada masa sekarang.
Gorga : Jurnal Seni Rupa

Volume 09 Nomor 02 Juli-Desember 2020 p-ISSN: 2301-5942 | e-ISSN: 2580-2380

\section{KAJIAN TEORI}

\section{Teori Pengembangan Kualitatif Randai}

Perancangan teater pola randai ini berpijak pada pengembangan kualitatif pertunjukan randai Pengembangan kualitatif y ang dimaksud adalah bentuk kreasi baru dalam pertunjukan randai yang meliputi perbaikan pitunggua ( $k u d a-k u d a)$, modifikasi gerak galombang, dan variasi tepukan galembong. Secara kualitatif, motif gerak silat yang digunakan sebagai penanda pergantian babak pun mengalami proses koreografi yang lebih variatif(Indrayuda, 2013: 117).

\section{Teori Well Made Play}

Bentuk dramatik pementasan Rambun Pamenan berangkat dari perwujudan teater moderen dengan penyajian well made play yang dikembangkan oleh Eugene Scribe (1791-1861). Ciri-ciri dasarnya adalah eksposisi jelas dalam menggambarkan situasi dan watak tokoh, pengolahan situasi s angat cermat menuju peristiwa berikutnya, suspens muncul tak terduga dan berbalik menuju logika, plot berlang sung kontinyu dan memuncak, resolusi terjadi secara logis dan meyakinkan (Yudiaryani, $2002: 168$ ).

\section{Teori Pemeranan}

Teori pemeranan yang digunakan dalam proses perancangan teater Rambun Pamenan adalah teori pemeranan dari Richard Boleslavsky. Di dalam bukunya yang berjudul Enam pelajaran pertama bagi Calon Aktor (di-Indonesiakan oleh Drs Asrul Sani, Jaya Sakti, Jakarta, 1960), Boleslavsky menjelaskan bahwa aktor harus melewti prosedur yang panjang untuk menciptakan peran. Prosedur tersebut antara lain, sebagai berikut: Konsentrasi atau Pemusatan pikiran, ingatan emosi, laku dramatis, pembangunan watak, pengamatan, dan irama.

\section{METODE PENELITIAN}

Adapun proses yang dirancang dalam usaha menciptakan Teater Rambun Pamenan, dibagi dalam tahap-tahap sebagai berikut :

\section{Observasi dan Eksplorasi Spektakel (Interpretasi Naskah)}

Metode perancangan karya-karya seni pertunjukan selalu mengacu pada perwujudan pemanggungan atau spektakel. Batasan spektakel adalah semua material y ang berada di atas pentas yang bersifat audio-visual, baik menyangkut aksi para pemeran maupun unsurunsur pemanggungan yang lain seperti setting, properti, kostum, lampu dan musik. Dengan demikian spektakel tidak bersifat statis tetapi sangatd inamis .

Tahap eksplorasi spektakel teater "Rambun Pamenan" merupakan rangkaian kreativitas yang bersifat kognitif 
untuk mencari kemungkinan-kemungkinan visual baik dalam bentuk penyusunan pola lantai pemeranan, pembuatan desain artis tik, mau pun penyusunan partitur musik. Aplikasi kongkret dari tahapan ini adalah analis is terhadap lakon baik melaui dukungan riset, observasi, studi pustaka maupun wawancara. Langkah kerja berikutnya adalah perancangan naskah lakon yang dikuti dengan penafsiran struktur lakon melaui reading yang dilakukan secara kolektif. Reading tersebut juga bertujuan dalam menjajaki kemampuan pemeran dalam kaitannya dengan tafsir pada tokoh, lebih khus us lagi pada pencarian karakter suara. Di luar proses kerja tersebut, tahap mencari-cari dilakukan dengan berbagai latihan Pemeranan. Pelaksanaan latihan tersebut diarahkan untuk mencari kemungkinan-kemungkinan bagi gestur, analogianalogi peran, dan menumbuhkan keterkaitan emosi terutama antar pemain.

\section{Memberi Isian Spektakel (Penciptaan Peristiwa)} Tahap memberi is ian spektakel merupakan cara kerja perancangan untuk mengembangkan aspek-aspek pemahaman lakon menuju pada aspek-aspek perwujudan visual. Pada tahap ini interpretasi lakon "Rambun Pamenan" diarahkan untuk memberikan dorongan semua pendukung (terutama pemeran) dalam mewujudkan akting verbal maupun non verbal. Penemuan penemuan yang masih bersifat 'kasar' tersebut, diolah untuk mendapatkan penekananpenekanan yang mampu menggambarkan inti peristiwa, perubahan suasana dan progresi emosi tokoh-tokohnya. Penekanan-penekanan ters ebut akan dihadirkan melalui penegasan pada sisi ekspresi mimik, impresipada keseluruhan akting pemeran, laku yang memperlihatkan motivasi dan penyikapan terhadap areal permainan. Aplikasi pada metode ini direalisasikan pada latihan pencarian bloking, improvis as i-improvisasi di luar desain akting, latihan diksi dialog yang mampu men ggambarkan "perbedaan" tokoh sekaligus dinamika karakternya. Latihan tersebut pada dasarnya adalah kreativitas untuk menciptakan 'peristiwa' atau 'suasana'.

\section{Pengembangan Spektakel (Penciptaan Dramatik)}

Tahap pengembangan merupakan usaha kreator "Rambun Pamenan" dalammengarahkan para pemeran untuk mewujudkan movement, gesture, bussines act, dalam bentuk lakuan atau gerak yang sudah memperlihatkan penghayatan. Para pendukung tersebut dibimbing untuk merasakan situasi dalam diri tokoh atau suas ana yang diperankan melalui bentuk akting dan gerak. Secara kongkrit bentuk latihan penciptaan teater "Rambun Pamenan" yang dilakukan dalam membangun keyakinan tersebut adalah latihan-latihani
Gorga : Jurnal Seni Rupa

Volume 09 Nomor 02 Juli-Desember 2020

p-ISSN: $2301-5942$ | e-ISSN: 2580-2380

penumbuhan imajinasi terhadap latar cerita, kesadaran ruang, kesinambungan antara aksi dan reaksi, dan posisi kejiwaan pemeran yang memperlihatkan empati.

Para penata dalam tahap ini mengembangkan perancangan musik dan set dekornya berdasarkan konsepsi auditif dan imaji ruang yang telah diperolehnya dari pengamatan pada tekstur pemeranan yang telah terbangun. Konsep perancangan tersebut pada dasarnya merupakan pengembangan dari desain artistik yang sebelumnya telah disimpulkan dari analisis teks atau lakon. Dengan demikian, dalams etiap latihan pengembangan, penatailus trasi maupun penata artistik sudah dilibatkan secara intensif. Hal ini penting karenan masing-masing unsur harus sudah memberi kontribusi bagi penciptaan dramatik yakni terjadinya perkembangan alur cerita yang memberi peningkatan ketegangan, dan sekaligus terbacanya peluruhan dalam alur atau jalannya cerita.

\section{Pemantapan Spektakel (Harmoni)}

Tahapan pemantapan merupakan kerja perancangan untuk menampilkan "Rambun Pamenan" secara utuh. Orientasi latihan diarahkan pada perhitungan irama, tempo, dan dinamika. Pusat konsentrasinya adalah pencapaian 'musikalitas' dalam pementasan. Musikalitas tersebut disusun secara berulang-ulang (melalui latihan dari awal hingga akhir lakon) dengan mengacu pada pembenahan ketegangan demi ketegangan, timing pada perubahan suasana, lompatanlompatan emosi tokoh, dan lambat-cepatnya dialog antar tokoh.

Pada tahap ini respon terhadap ruang (dan dukungan ilus trasi musik terhadap suasana demi suasana, sudah mulai dihadirkan dalam visualisasi yang masih global. Tujuan pengadaan set-dekor dan ilustrasi yang masih belumpermanen ini adalah untuk mematangkan gestur pemain, membakukan jarak tempuh movement, dan menyeleksi berbag ai unsur artistik dan musikalitas agar tercapai harmoni dalampementasan.

\section{HASIL DAN PEMBAHASAN}

\section{Hasil}

\section{1). Adegan 1}

Belum Sampai waktu tiga bulan datuk Katumangguangan (suami Puti Linduang Bulan) meninggal dunia, datanglah Rajo Angek Garang Meminang Puti Linduang Bulan. Pinangan tersebut kontan saja ditolak oleh Puti Linduang Bulan, Rajo Angek Garang marah dan akhirnya Puti Linduang Bulan berhasil di bawa paks a oleh Rajo Angek Garang keistannya Nagari Subarang Angin. Kepergian Puti Linduang Bulan meninggalkan Luka yang Mendalam 
Bagi dua Anaknya yang masih kecil yaitu Puti Reno Pinang dan Rambun Pamenan.

\section{2). Adegan 2}

Rajo Angek Garang mencoba merayu Puti Linduang Bulan untuk menjadi istrinya ketika Puti Liduang Bulan telah sampai di Subarang Angin. Rajo Sangek Garang begitu berharap, sampai-s ampai ia menjanjikan segala harta kekay aan y ang dia miliki akan ia serahkan kepada Puti Linduang Bulan, as alkan Puti Linduang Bulan bersedia menjadi pendamping hidupnya. Akan tetapi Puti Linduang Bulan tetap bertahan dengan keputusannya untuk menolak pinangan tersebut. Rajo Angek Garang-pun naik pitam dan memerintahkan parajuritnya untuk memasukkan Puti Linduang Bulan ke dalam Penjara bawah tanah yang tempatnya berdekatan dengan kandang babi.

\section{3). Adegan 3}

Ketika Rambun Pamenan sudah mulai menginjak dewasa, ia menanyakan keberadaan orang tuanya kepada kakaknya Reno Pinang. A walnya Reno Pinang agak keberatan menceritakannya, tetapi karena Rambun Pamenan begitu memaksa, akhiranya Reno Pinangpun bersedia menceritakannya. Hal ini dilakukan Reno Pinang karena Rambun Pamenan dianggap sudah sepatutnya mengetahui rahasia yang selama ini selalu tersimpan rapi, terutama perihal ibunya Puti Linduang Bulan. Begitu cerita itu sampai ke Rambun Pamenan kontan saja Rambun Pamenan terlihat begitu emosi dan saat itu juga Rambun Pamenan memutuskan untuk segera menjemput ibunya Puti Linduang Bulan yang ditawan oleh Rajo Angek Garang.

\section{Pembahasan}

Pementas an lakon "Rambun Pamenan" akan bertumpu pada tiga kekuatan utama randai, yakni kaba, galombang, dan dendang sebagai penegas suasana. Setting yang bersifat simbolik dan dihadirkan melalaui syair dendang, merujuk hal ters ebut maka penyusanan spektakel menjadi bersifat impresionis atau simbolik Ketiga kekuatan randai tersebut akan di tampilkan secara padu untuk menciptakan suatu impresi yang secara umumdiarahkan untuk mencapai efek tragik.

Dendang yang berfungsi sebagai narator akan menempatkan kesenian tersebut sebagai pengantar cerita, pemberi informasi berbagai latar belakang karakterdan kejadian. Dalamfungsinya sebagai narator tersebut Dendang juga merealisasikan teknik alinasi yang pada esensinya adalah mematahkan setiap 'empati' yang berlebih-lebihan dari penonton dan menyadarkan mereka kembali bahwa yang tersaji di
Gorga : Jurnal Seni Rupa

Volume 09 Nomor 02 Juli-Desember 2020

p-ISSN: 2301-5942 | e-ISSN: 2580-2380

depannya adalah totonan. Teknik ini bertujuan untuk menempatkan penonton agar terlibat secara kritis atas apa yang terjadi di atas panggung. Fungsi ini ini juga berlaku ketika dendang diposisikan sebagai transitor atau penjeda perubahan adegan.

Penyusunan spektakel yang bersifat simbolis adalah penghadiran setiap elemen keaktoran dan tata panggung untuk menyikapi alur yang bersifat linear. Alur tersebut ditandai dengan perpindahan peristiwa atau adegan yang berlangsung cepat namun tetap berurutan. Sus anan alur tersebut akan diikuti dengan gaya keaktoran tertentu dan penataan artistik khusus. Dalam keaktoran, untuk menyikapi pengadegan yang bersifat linear tersebut maka seluruh instrumen keaktoran akan dimaksimalkan. Instrumen tersebut meliputi Tari (galombang), dendang, seni peran dan pengaturan bloking yang berdasarkan sugesti imajin asi y ang ditimbulkan oleh Pandendang.

Secara umum, bentuk karya ini merupakan penciptaan formula baru dari berbagai idiom idiom tradisi yang dipergunakan sebagai titik tolak dalam berkarya. Formulasi terebut bukan sekedar mencangkok, meminjam, atau meniru konvensi (Barat) secara 'otentik' tetapi merupakan kreativitas untuk menciptakan kebaruan (inovasi). Salah satu inovasi tersebut adalah dengan membuat perancangan visual dan isian (content) yang baru. Perancangan tersebut secara esensial merupakan proses kreatif untuk mengaksentuasikian budaya daerah (Minangkabau) dan menjadikan kekayaan budaya daerah tersebut tetap relevan untuk kehidupan masa kini (modernitas), sehinga dapat dinikmati oleh seluruh masyarakat Indonesia.

Perwujudan bentuk lakon "Rambun Pamenan" ini merupakan penafsiran ulang untuk menekankan penggambaran berbag ai persoalan seperti keserakahan, ambisi, degradasi moral, kekuasaan dan adat istiadat, yang pada dasarnya adalah persoalan setiap rakyat di negeri ini. Kisah "Rambun Pamenan" juga mengambil latar cerita keberadaan Minagkabau dengan segala adat istiadatnya, yang rentang menimbu lkan penyimpangan di kalangan pelakunya.

Secara umum penyajian teater dalan "Rambun Pamenan" akan ditampilkan dalambentuk visual yang mengacu pada pola kesenian tradisi Randai. Hal ters ebut merupakan sebuah us aha dalam mengangkat kesenian tradisi Minangkabau sekaligus merevitalisasi kembali seni tradisi agar seni tradisi Minangkabau dapat hadir kembali dalam hati masyarakat secara 


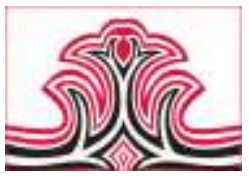

umum untuk melestarikannya.

kemudian tergerak dalam

Merujuk penuturan di atas di atas, maka selunuh spektakel pertunjukanpun akan dihadirkan dalam kemas an y ang masih dapat dikategorikan dalambentuk realisme. Dalam perkembangannya, bentuk realisme merupakan cerminan 's epotong kehidupan', s ehingga seni panggung merupakan penyajian kembali kehidupan inderawi secara obyektif bahkan 'mendekati' s erinci mungkin dengan kenyataan (Bakdi Soemanto, 1996: 6-7). Itulah sebabnya, Realisme berusaha mewujudan apa yang disebut "ilusi realitas". Konsep ini menegaskan bahwa realisme harus mampu 'memindahkan' kenyataan s ehari-hari diatas panggung, bukan dalam bentuk penggayaan (stilisasi) atau merusak (mendistorsi), tetapi menyajikannya setepat mungkin sehingga ilusipun tercapai. Pun begitu realisme yang dihadirkan tetap saja merupakan 'representasi' kenyataan yang tak bisa menghindari 'pembesaran' dan 'pengemas an' realitas atau peristiwa yang sesungguhnya.

\section{KESIMPULA DAN SARAN}

\section{Kesimpulan}

Lakon "Rambun Pamenan" menegaskan satu premis: bahwa nilai manus ia tidak bis a dilihat dari 'permukaan' tetapi hanya bis a dis impulkan dari prilakunya (attitude) dalam keseharian. Inilah universalitas nilai yang sebenarnya sangat menarik untuk di kedepankan terlebih untuk mengaksentuasikan nilai-nilai is lami sebagai karakter paling hakiki dalam s pirit ke-Melayuan.

Lakon "Rambun Pamenan" dikemas dalampertunjukan randai y ang masih dapat digolongkan dalamteater gaya realisme. Berpijak pada gaya pementasan realisme (presentatif) tersebut maka bentuk-bentuk pengadaptasian, pengolahan-pengolahan naskah secara 'radikal', perubahan-perubahan struktur dramatik sama sekali tidak menjadi bagian dari konsep kerja penyutradaraan. Pijakan yang menjadi acuan dalam konsep penyutradaraan lakon "Rambun Pamenan" adalah berpedoman pada jalinan konflik yang otentik dari naskah tersebut.

\section{Saran}

Pertunjukan teater modern berbasis seni tradisi adalah upaya melestarikan seni tradisi secara kreatif. Cara ini adalah inovasi yang perlu dikembangkan karena di tengah-tengah peradaban yang terus berkembang ini. Cara ini juga dapat membuat seni tradisi dapat berkembang dan diterima oleh masyarakat modem. Namu, di dalam proses modernisasi seni tradisi, hal
Gorga : Jurnal Seni Rupa

Volume 09 Nomor 02 Juli-Desember 2020

p-ISSN: 2301-5942 | e-ISSN: 2580-2380

yang perlu diperhatikan adalah batasan eksplorasi. Jangan sampai upaya modernis asi seni tradisi malah merus ak seni tradisi itu sendiri.

\section{DAFTAR RUJUKAN}

Bolelavsky, Richard. (1985). Enam Pelajaran Pertama Bagi Calon Aktor. Jakarta: Yayasan Citra.

Soemanto, Bakdi. (1997). Pengaruh Drama Realisme dalam Teater Indonesia. Yogyakarta:

Stanislavsky, Konstantin, Terj. Asrul Sani. (1985). Persiapan Seorang Aktor. Jakarta: Yayasan Citra.

Indrayuda, dkk. (2013). Randai : Suatu Aktivitas Kesenian dan Media Pendidikan Tradisional, Padang: Dinas Kebudayaan dan Pariwisata Sumbar.

Yudiaryani. (2002). Panggung Teater Dunia, Yogyakarta: Pustaka Gondosuli. 